\title{
Advanced Management Training for Sustainable Development of the Mining Region
}

\author{
Tatjana Panina ${ }^{1, *}$, and Sergej Dochkin ${ }^{1}$ \\ ${ }^{1}$ T.F. Gorbachev Kuzbass State Technical University, 650000 Kemerovo, Russian Federation
}

\begin{abstract}
The article presents the experience of advanced training and retraining for mining enterprises in the region. Special emphasis is placed on the training of specialists required for the management of innovative production, solving the problem of digital transformation of the economy. The analysis revealed the need to change approaches to learning and transition to new trends aimed at the formation of a new level of specialist with cross-functional knowledge on a wide range of issues and expertise in one of the subject areas. The achievement of such results in training is based on the introduction into the educational process of Advanced Learning Technologies components, involving the merger of "learning" and "e-learning" environments, the creation of an intellectual learning environment; taking into account the individual needs and abilities of trainees; offering individual learning paths. The presented approaches are implemented within the framework of the Presidential program of management training for the national economy, which presents technologies and special training modules on the use of digital technologies and platform solutions in the economy and management.
\end{abstract}

\section{Introduction}

At present, Kuzbass as an industrial region of Russia is going through a difficult period. The predominance of the commodity sector in the industrial specialization of the region's economy leads to a significant dependence of the socio-economic situation in the region on the situation in commodity markets; the technological lag of the region in the manufacturing sector and the low level of investment increases the risk of losing the competitiveness of the region's economy in the short term. As a result, the lack of infrastructure for the implementation of promising investment projects, the reduction of demographic potential and the imbalance in the labor market demanded serious and active measures to change the situation. The "Strategy of socio-economic development of the Kemerovo region for the period up to 2035" developed in the region has become a tool aimed at a comprehensive solution of problems that can equalize the situation, significantly reduce the impact of global risks, to maximize the opportunities associated with the digital transformation of the economy and social sphere of the country [1].

\footnotetext{
*Corresponding author: idpo@kuzstu.ru
} 


\section{Materials and Methods}

According to the adopted Strategy, the aim of socio-economic development of the Kemerovo region is to ensure the advanced rates of development and competitiveness of the economy and social sphere, as well as to achieve a leading position in the quality of life and the level of human capital development. One of the key tasks in the areas of strategic development of the region is the modernization of the system of secondary vocational and higher education under the projected changes in the labor market within the strategic direction for the development of human capital and quality of life [2]. It is the solution of this problem that will solve the problem of providing modern production and business structures created during the implementation of the Strategy with qualified personnel.

The analysis carried out by us in the Federal state budgetary educational institution of higher education "T. F. Gorbachev Kuzbass state technical university", KuzSTU for short, showed that currently improving the development of the region's economy, including the introduction of priority innovative projects in the production process, there is a tendency to use the available opportunities not in full measures. And one of the reasons that hinder innovation activity is the level of qualification and poor motivation of employees [3]. There is a low awareness of the personnel regarding the prospects of the latest developments and the possibility of their introduction into production, on the one hand, and on the other hand, there is a fact that the modern professional qualification of employees of most enterprises does not meet the requirements of innovation policy. The problem is not in the weak university training of an employee, but in the insufficient systemic attitude to his continuous education.

Accordingly, the University has launched a system of additional professional education, providing advanced training and professional retraining of specialists for the industry of the region (coal mining and processing, metallurgy, chemical industry, engineering, construction, etc.). During the period from 2012 to 2018,714 people took professional retraining and 8615 people received advanced training. Analysis of the data showed that there is a tendency to the reduction in the number of employees, which are regularly sent to KuzSTU for advanced training and professional retraining by directors of enterprises, on average by $10-12 \%$ per year [3]. This is contrary to the recommendations that business leaders should continuously conduct training and retraining of new employees and specialists, as nothing stands still. As the production process is constantly modernized, it is important to be able to respond to changes in a timely manner, as only together with the human resources the research and development will be the key to the continued success of the organization. However, the management of enterprises and organizations does not conduct continuous systematic work in this area, which requires to provide training of employees at least once every three years.

Partially, the need for professional retraining and advanced training of personnel in enterprises is solved with the help of internal training, in their own corporate universities and training centers. However, it should be recognized that modern scientific developments can be presented to trainees more in universities. In addition, only in the University environment is possible to accumulate the experience of different enterprises during briefings, training events and business games, which is especially important for the training of middle and senior managers. Exchange of experience, familiarity with innovative practices always lead to mutually beneficial cooperation, especially when it comes to innovative developments. In accordance with the strategic plan (roadmap) for the development of innovation policy in Russia, and Kuzbass in particular, most enterprises should move to the development of optimal models of management of advanced technologies that can ensure the management of innovative processes and increase the projects' productivity. This requires the training of a manager with new competencies, with 
experience in project work, able to competently organize the selection and activities of the project team, taking into account the professional abilities and psychological characteristics of each employee during the transformation of the company (enterprise).

It is for the training of managers of this level that the University has been implementing the Presidential program of training of managerial personnel for the national economy for more than twenty years. Its purpose is to provide enterprises and organizations of the national economy of the region and Russia with highly qualified specialists in the field of management and organization of production that meet the modern requirements of the economy, able to work effectively in market conditions, familiar with the management culture and experience of leading foreign countries.

\section{Results and Discussions}

Over the past two decades, a lot of experience has been accumulated in the implementation of the program, and in the implementation of proposals made during its development, in the practice of real production: up to $60 \%$ of the developed projects are put into practice within three years, up to $40 \%$ of them are put during the first year. At the same time, the study showed that students at the initial stage are particularly poorly proficient in project management skills (52\%), have only a superficial understanding of the stages and phases of the project (33\%), have no experience with stakeholders $(71.3 \%)$ and do not know the methods of selection and team building (43\%). It is established that the success of any project depends on the professional level and qualifications of each team member performing certain functions, having a specific level of responsibility and interested in achieving the end result, therefore specialists in the field of enterprise management must be trained within the project environment and teamwork.

Taking into account the obtained data, the program was adjusted with the aim of providing trainees with management and communication skills required for an effective leader, focusing on project team work, as it is a team of key personnel (management team) is a crucial strategic resource for any company.

The basis of our training was the concept of "T-shape - persons", as the basis of the model of a modern specialist-manager, that is able to form a professional in the field of production management, who is ready for constant change, modification and development [4]. This concept is based on the development of cross-functional knowledge in a specialist on a wide range of issues and the achievement of deep (expert) knowledge in one of the subject areas. Thus, such a "T-shaped" concept is a figurative representation of the depth and breadth of knowledge of each manager, harmoniously combining the breadth of skills and experience in a particular area (cross domain skill and attitudes) with the breadth of skills and opportunities to work together in various disciplines (the depth of learning) with similar employees (experts in other fields) and the application of knowledge in areas other than their own [5]. For managers, this means not only having deep managerial knowledge, but also having qualities such as the ability to put yourself in the shoes of another person, communication skills, team building skills and the ability to work together or interpersonal skills. The development of "T-shaped" skills of management specialists, who are trained at the Presidential program, is a decisive factor for a successful career at the end of the training.

In the concept of "T-shape - persons" during the training we focused on the formation of three groups of abilities: the synthesis of ideas from different areas, the ability to learn quickly, the ability to develop [6]. This required a shift from a one-discipline approach to a multi-discipline approach aimed at improving the development of team skills, which would allow any enterprise to remain competitive. By adjusting the curriculum and the list of programs, we implemented an approach that allowed us to prepare trainees for leading roles 
in the development of innovative projects, entrepreneurial initiative, management consulting, organization of knowledge-intensive production and financial services [7].

To do this, we have revised the curriculum of the program. New disciplines such as "change management", "project management" were introduced, special courses "personal effectiveness of the director", "norms of business communication in the economic sphere", "tools of the Internet marketing in the promotion of goods and services", "PR-technology in professional activities" were added since 2014.

Since 2019 the trainees have been offered a computer business game "Business course. Maximum", which has allowed them to create a virtual economic environment in which each of the participants has had the opportunity to work out the skills of enterprise management. In the course of the game, the trainees were offered to equip the enterprise, to load all the shops of the enterprise for the production of all three types of products; to build a sales policy with the help of analytical data; to show the best rating indicators for the results of each year and at the end of the game session; on the basis of management decisions to get ahead of its competitors by rating, which is formed from the values of net profit, return on equity and the market price of shares.

In the course of four rounds, the participants of the game consolidate the previously acquired theoretical knowledge of economic and managerial disciplines in practical actions in the management of the enterprise in a time limit; master the competencies of the formation of competitive and marketing policy of the enterprise; develop organizational and managerial competencies in the preparation of management decisions and leadership of the working group; work out communication competencies in the course of intra-group communication, teamwork, final presentations and briefings.

For the past four years, the participants of the Presidential program have actively been working in the e-learning system of the University, created on the basis of Learning Management System Moodle. It allowed us to provide deep involvement of the trainees in the active educational process, to create conditions for active interaction of participants and teachers, to enrich each participant of the educational process with personal experience at the expense of training in the active environment of interaction in the off-line and on-line mode. Interactive lectures on 4 educational modules of the program allow you to expand the content of the issues addressed in the classroom, to consolidate the material or to study it again, if any lesson was missed [8]. At the same time, the presence of lectures with a nonlinear structure and with the assessed material allows to activate the process of mastering and control the actions of students in the system. However, the study of theoretical material can not prepare a competent and proactive leader. Therefore, more than $63 \%$ of the materials uploaded to the system are devoted to practical classes, during which the trainees, for example, calculate various economic factors, such as time, the ratio of supply and demand in the market, the amount of financial resources, relations within the team, agree on methods for assessing the achievement of goals; prepare a career promotion policy, build internal communications in the team and develop strategies and manage them. More than $80 \%$ of students noted the convenience of working with such courses and tasks, allowing them to perform at a convenient time, but within the defined deadline.

During each of the modular courses included in the program of professional retraining, trainees work with computer tests that implement on-line testing, developing communication skills with the subsystem of students' support of LMS. Developed skills allow trainees to pass the Federal final testing in the final examination in a foreign language, economic subjects and administrative preparation confidently [3]. For example, $89.1 \%$ of students from the last issue received excellent marks based on the results of the final test.

In fact, our actions in the course of training for mining companies in the region are based on the use of so-called ALT-technology (Advanced Learning Technologies). The 
advanced Learning Technologies implemented by us, at the first stage, involve the merger of "learning" and "e-learning" environments, which will lead to the creation of an intellectual learning environment; taking into account the individual needs and abilities of students $(36 \%$ of which are currently middle managers who are part of the personnel reserve of their enterprises); offering individual learning paths. At the second stage, the implementation of automated adaptation of educational content for an individual is planned, as well as the use of adaptive systems in the electronic educational environment of the University, combining the capabilities of artificial intelligence, machine learning, virtual and supplemented reality, analysis of large amounts of data [3].

At the first stage in the ALT-concept for training in the disciplines of "Economics for managers", "Management of organizations", "Financial management", "Organizational behavior", "Psychological management" on the basis of Change approach multimedia technology, "flipped classroom" technology, interactive content, and on-line learning are involved. The last one is highly flexible and easily adaptable to the specific features of the trainees. During the development of disciplines "Project management", "Change management", "Competitive strategy of the enterprise and analysis of the commodity market" gamification methods are in the basis, project activities are organized; online evaluation and economic simulators, as well as storytelling are used. The transition to the second stage will allow to implement the Disrupt approach, which is designed for the active use of technology of pedagogical design, technology of joint training, technologically supported methods of development of thinking skills, virtual and augmented reality, as well as it will fully allow to move to adaptive learning.

The emphasis on digital technologies in the process of the management training in the Presidential program allowed the KuzSTU to respond quickly enough to the approval of the new national project "Digital economy" and the training tasks defined by the project [9]. According to the national project "Digital economy" it is expected to increase internal costs for the development of the digital economy, the creation of a stable and secure information and telecommunications infrastructure for high-speed transmission, processing and storage of large amounts of data, the use of mainly domestic software by state bodies, local governments and organizations. The solution of such problems is impossible without managerial personnel with a high level of digital competence in the management of modern enterprises, primarily working in the coal industry [10].

According to our research, only $78.6 \%$ of enterprises have their own corporate university or corporate training center, respectively, about a quarter of industry employees are potential consumers of additional educational services that the Kuzbass State Technical University can provide. At the same time, only about $50 \%$ of respondents use modern simulation equipment, virtual simulators, on-line training and video content. The degree of use of digital technologies in the management system is also quite high (up to $64 \%$ of enterprises), which requires constant updating of personnel on "digital management". Indeed, despite the relatively high degree and wide range of equipment and information systems (HRM, ERP, BPM, CRM, DBMS, data center, etc.), digital transformation in the coal industry is present only at the level of large Federal holdings [10, 11]. Some companies use only certain elements of digital technology, without bringing digital information to strategic priorities, has a low level of systematization of data and system analytics, some digital technologies have not fully reached the manufacturing enterprises.

In this regard, the Presidential program of management training for the national economy is adjusted to match the processes of digitalization of the mining industry: special courses on robotic and remotely controlled equipment, on the work of managers at remote centralized control rooms, the introduction of three-dimensional models of enterprises to optimize their design and management, a special training module on the introduction of digital technologies and platform solutions in the economy are developed [10]. The new 
module provides the development of such disciplines as "Career development in the digital economy", "Business analysis in the digital economy", "E-Commerce and the digital market". A special place among the disciplines "Modern forms of enterprise management", "Innovation management", "Project management" will take the study of the integration of industrial-level automation systems with business applications [12]. On the basis of the scientific laboratory of labor productivity of the Kuzbass State Technical University for the trainees an elective course on the use of digital technologies was developed to provide methodological and organizational support to improve productivity in enterprises $[13,14]$.

The adjustment of the program will allow the audience to consider and develop a single cycle of planning, execution, accounting and analysis activities of the enterprise, thereby increasing the flexibility of the management system, drastically reducing the reaction time to the changing environment in the course of operational management and enhance the validity of management decisions.

\section{Conclusion}

The main results of the participants' training, taking into account the initiated digital transformation of the region's economy, are reflected in the final certification works (Training program 2018-2019) - about 16\% (last year - 13.7\%) of all works contain proposals in the context of the digital economy. For example: "Training of specialists to work in the mode of digitalization in agricultural enterprises", "Project management of the implementation of the automation system of management and operation of the housing complex", "Marketing strategy of the University to promote additional professional programs in the conditions of digitalization of higher education", "Management of automation processes while working with apartment buildings", "Introduction of electronic document management system as a factor to improve management efficiency" [15].

These approaches to the activities of the University correspond to the Program of development of additional professional education of the Kuzbass State Technical University until 2020 and can improve the competitiveness of educational organizations in the market of educational services in the region and the country.

\section{References}

1. A.Krechetov, A.Khoreshok, V.Blumenstein, E3S Web Conf., 21, 0001 (2017)

2. A.Krechetov, E3S Web Conf., 41, 0001 (2018)

3. T. Panina, S. N. Kostyuk, S. Dochkin, E. Pahomova, Dilemas contemp.: Ed., Pol. and Val., 6, 4 (2019)

4. D. Guest, J. Paauwe, P. Wright, HRM and Performance: Achievements and Challenges (Wiley, London, 2013)

5. R. Patterson, The T-Shaped Person: Building Deep Expertise AND a Wide Knowledge Base (Wiley, London, 2018)

6. T. Brown, Change by Desingn: How Desing Thinking Transforms Organizations and Inspires Innovation (Hasper Collins, London, 2009)

7. S. Korolev, T-shaped Skills in Product Development (Science, Moscow, 2018)

8. V. Bobrikov, N. Ravichkin, V. Shshenniko, E3S Web Conf., 41, 04014 (2018)

9. A. Khoreshok, A. Kuznetsov, A. Shalkov, E3S Web Conf., 41, 03004 (2018)

10. I. Pevneva, O. Gavrishina, A. Smirnova, E. Rozhneva, N. Yakimova, E3S Web Conf., 21, 04021 (2017) 
11. A. Kovalev, N. Rebrova, M. Zhidkova, E3S Web Conf., 41, 04026 (2018)

12. O. Kalenov, S. Kukushkin, E3S Web Conf., 41, 04025 (2018)

13. O. Ivanova, G. Antonov, S. Bereznev, E3S Web Conf., 15, 04001 (2017)

14. L. Kusurgasheva, O. Nedospasova, E. Zhernov, E3S Web Conf,, 15, 04007 (2017)

15. V. Ovchinnikov, D. Kochergin, A. Blinov, T. Logunov, E3S Web Conf., 41, 04053 (2018) 